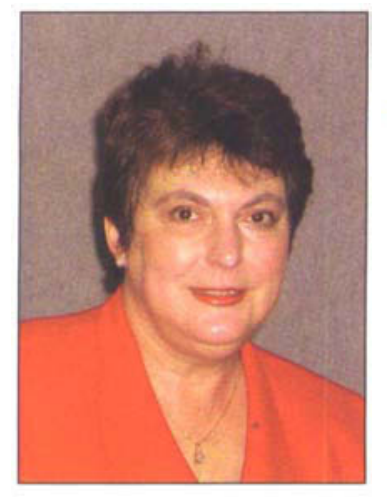

\title{
Human Resources equipped to serve a dynamic California
}

KAREN VARCOE

Human Resources Program Leader alifornians numbered 34.3 million in January 2000, growing $1.7 \%$ in one year. At that rate of growth, our numbers will reach 50 million by 2025, challenging the state's social, economic and environmental resources.

As these challenges mount, UC Cooperative Extension's (UCCE) Human Resources Program is increasingly called upon to solve new problems. Human Resources faculty at UC Berkeley, UC Davis and UC Riverside, in concert with a network of UCCE advisors in California's 58 counties, extend university research to youth, families, businesses and public policy makers. The program now encompasses family and consumer sciences, human health and nutrition, youth development and $4-\mathrm{H}$, and community development.

Like other UCCE programs, Human Resources has the ability to respond rapidly to changing social and economic conditions, whether local or statewide, with innovative programs and activities.

One recent example was a research and education effort launched by Alameda County Cooperative Extension personnel in 1992. They designed "Grandparents Are People Too!" to assist the growing number of grandparents parenting grandchildren (see p. 10). Nationwide, the proportion of children under 18 living in grandparent-headed households had increased by more than $50 \%$ between 1970 and 1990. In 1990, 493,000 of California children lived in such households, $6.4 \%$ of all children statewide. That rate was significantly higher than the national average of $4.9 \%$. UCCE staff compiled data to establish a statewide client base and to prioritize needs, essential components for future program development.

Human Resources programs offer opportunities for at-risk families to break out of the downward spiral in which they find themselves by equipping them with new skills for managing their resources and building futures.

However, assisting families has become more complex in an environment of rapid population growth and change. More immigrants come here than to any other state, accounting for $74 \%$ of our growth. Recent arrivals are likely to have a higher number of children per family, an average of over 3.5 in the case of Hispanic immigrants. In less than 50 years, Asians and Hispanics together will make up more than two-thirds of California's population; already in $1998,46 \%$ of the children in California were Hispanic and $11 \%$ were Asian. The counties that have the largest immigrant populations also have the highest rates of people living below the poverty level.

With this growing population come the stresses of diverse ethnic and cultural groups living close together and competing for scarce resources. Youth and adults continue to turn to drug and alcohol abuse, gang activity and crime. The increase in youth violence is a major concern. In 1995, the percentage of California children living in "high risk" families was $17 \%$, as compared to $14 \%$ for the country as a whole, according to the 1999 Kid's Count Data Book, published by the Annie E. Casey Foundation.

Adding to the challenge is the fact that the population is growing at both ends of the age continuum. Youth under 18 now make up $28 \%$ of California's population. The Casey Foundation estimates that the state's youth will increase to $29 \%$ of the total, or more than 10 million, by 2005 - with most of the added children living in low-income, minority families in urban areas.

At the other end of the age spectrum, Californians over 65 now make up $11 \%$ of the state population, about 3.5 million. The state's elderly population is expected to rise dramatically, both in absolute numbers and as a percentage of the total, as the Baby Boomers reach retirement age early in the 21 st century.

Programs can be designed to meet the needs of target populations, whatever their circumstances. However, such efforts require county-by-county research, development, testing and implementation. University funding enables us to develop and, in some cases, to launch new programs, but we must seek outside sources of funds if we are to implement programs broadly enough to make a difference to our target populations. In recent years, it has become more and more difficult to obtain local funding for needed programs; many cities and counties, especially those in rural areas, are having trouble meeting the most rudimentary of their residents' needs.

There are some bright spots in this picture. One positive innovation is the result of voter-approved Proposition 10, through which Children and Families Commissions allocate tobacco taxes to fund programs for children, from infancy to age 5, and their families. Many Human Resources advisors in the state have successfully applied for these funds and are now implementing programs to improve the well-being of children in their counties. Further, grants from private foundations and corporations are beginning to replace government allocations to fund a wide variety of social interventions.

Societal and economic changes - ranging from rapid population growth, to increased drug use in rural areas, to a statewide economic downturn - are putting intense pressure on families across the state, on every level of government, and on every organization that works with community needs. The challenges have never been greater for UCCE's Human Resources Program, an organization that has and will continue to have significant impact on the lives of Californians. 